\title{
Colicin E2 Production and Release by Escherichia coli K12 and Other Enterobacteriaceae
}

\author{
By ANTHONY P. PUGSLEY, *1 NICOLAS GOLDZAHL ${ }^{1}$ aND \\ RUTH M. BARKER ${ }^{2}$ \\ ${ }^{1}$ Unité de Génétique Moléculaire, Institut Pasteur, 25 Rue du Dr Roux, Paris 75724, France \\ ${ }^{2}$ Microbiology Department, University of Dundee Medical School, Ninewells Hospital, \\ Dundee DDI 9SY, UK
}

(Received 5 March 1985; revised 12 June 1985)

\begin{abstract}
Previous work has shown that Escherichia coli $\mathrm{K} 12$ ColE2+ cells undergo a form of partial lysis and exhibit increases in lysophosphatidylethanolamine (lysoPE) and free fatty acid content due to activation of phospholipase $\mathrm{A}$ when induced to produce and release colicin E2. The increase in lysoPE content was assumed to be essential for efficient colicin release. These same characteristics are also presented by some natural ColE2+ isolates, and by other representatives of the Enterobacteriaceae after transformation with derivatives of a ColE2 plasmid. However, Salmonella typhimurium strains carrying ColE2 plasmids released colicin without partial lysis and without increasing their lysoPE content. A previously undetected minor phospholipid, which appeared in these and other strains only when they were induced to produce colicin, may be an important factor in colicin release. In ColE2 $2^{+}$E. coli $\mathrm{K} 12$, production of this new lipid was dependent on phospholipase A activation following expression of the ColE2 lysis gene. Some other ColE2 ${ }^{+}$strains did not respond to induction of colicin production in the same way as $\mathrm{ColE}^{+}$E. coli $\mathrm{K} 12$. These strains were less sensitive to inducer (mitomycin $\mathrm{C}$ ) or unable to produce increased amounts of colicin in response to induction, or unable to degrade colicin once it was released. In general, the results suggest that colicin release occurs by the same or similar processes in the various strains tested, and support the continued use of $E$. coli $\mathrm{K} 12$ as the model strain for studying the mechanisms of colicin release.
\end{abstract}

\section{INTRODUCTION}

The processes of colicin E2 production and release have been extensively characterized in the laboratory strain Escherichia coli K12 (reviewed by Pugsley, 1984a). The eventual release of colicin E2 into the medium is the culmination of a sequence of events which starts with the induction of the plasmid-borne colicin E2 operon by inactivation of the chromosome-encoded repressor, LexA protein. In the laboratory, this is usually achieved by activating the host cell SOS regulatory circuit by treating the cells with normally sub-lethal doses of mitomycin $\mathrm{C}$. The cells then produce and accumulate large amounts of the colicin E2-immunity protein complex, the product of the first two genes $(c e u B$ and $c e i B)$ of the colicin E2 operon (Cole et al., 1985). The induced cells also produce lower amounts of a small, envelope lipoprotein called the lysis protein (Cole et al., 1985). After 2-3 h, the endogenous PldA phospholipase is activated, provoking significant changes in envelope phospholipid composition which are apparently essential for efficient colicin release (Pugsley \& Schwartz, 1984). The cells then start to release colicin, and simultaneously become permeable to sucrose and other normally impermeant solutes (Pugsley \& Rosenbusch, 1981, and unpublished data), become sensitive to lysozyme and to SDS (Pugsley \& Schwartz, 1984), cease all metabolic activity, and lose viability (Pugsley \& Rosenbusch, 1981 ;

Abbreviations: FFA, free fatty acid; PE, phosphatidylethanolamine; PG, phosphatidylglycerol; PS, phosphatidylserine; ONPG, $\alpha$-nitrophenyl $\beta$-D-galactoside. 
Pugsley \& Schwartz, 1983a). The cells also release some other, mainly periplasmic proteins along with the colicin (Pugsley \& Rosenbusch, 1981). The culture turbidity begins to decline at this time, but this can be prevented, without affecting colicin release, by including $20 \mathrm{mM}-\mathrm{Mg}^{2+}$ in the growth medium (Pugsley \& Schwartz, 1984). A similar sequence of events is involved in the production and release of other colicins encoded by small, high copy number plasmids (A, D, E1, E3, E8, N and DF13; reviewed by Pugsley, 1984a).

E. coli $\mathrm{K} 12$ is not a natural colicin-producing strain. It has been stored, manipulated and intentionally or unintentionally mutagenized during its prolonged existence as the standard laboratory E. coli strain. Furthermore, its envelope structure differs from that of most other Enterobacteriaceae in that it lacks the long polysaccharide side chains which are normally attached to the lipopolysaccharide core sugars on the cell surface (Lugtenberg \& van Alphen, 1983). All of these features could conceivably affect the way in which ColE $2^{+}$derivatives of $E$. coli $\mathrm{K} 12$ respond to induction of colicin production, so that some of the events which we previously considered to be important for efficient colicin release may in fact only occur in $E$. coli $\mathrm{K} 12$. In order to test this possibility, we selected a variety of natural and laboratory-constructed $\mathrm{ColE} 2{ }^{+}$derivatives of different representatives of the family Enterobacteriaceae and examined their responses to induction of colicin production.

\section{METHODS}

Strains, plasmids and bacteriophages. The strains of E. coli $\mathrm{K} 12$ used are listed in Table 1. Strain PAP542 was constructed by subcloning the entire colicin E2 operon (ceaB-ceiB-celB; Cole et al., 1985) into plasmid pOM40 (Raibaud et al., 1984) and then integrating it into the malA region of the chromosome of strain PAP488 by homologous recombination followed by spontaneous loss of the pOM40 derivative (Raibaud et al., 1984). The biuB mutation resulting in the loss of colicin E2 receptor activity was introduced into this and other strains by simultaneous selection for resistance to colicin E5 and to bacteriophage BF23 (Pugsley, 1985). ColE2 ${ }^{+}$Shigella $^{2}$ sonnei $\mathrm{P} 9$ and $E$. coli $\mathrm{CA} 42$ are standard colicin E2-producing strains. Other ColE2 ${ }^{+}$strains (Table 3 ) were selected from a collection of $\mathrm{Col}^{+}$strains by the fact that they appeared to produce only colicin E2 (Pugsley, 1985). Other strains (Table 3) were selected for study because they were sensitive to the antibiotics kanamycin, ampicillin and tetracycline, did not produce colicin or substantial amounts of any other protein (potential bacteriocin), lyse, or undergo significant changes in lipid composition when grown in L broth containing mitomycin C (see below), did not flocculate when grown in liquid culture, and were transformable by pAPIP219 or pCHAP16 (see below).

ColE2-related plasmids are listed in Table 2. Plasmid pCHAP16 contains approximately 4000 bp of pColE2-P9 DNA cloned in pBR322. pCHAP23 is similar to pAPIP692 (Pugsley \& Schwartz, 1983b) except that the vector DNA is pEMBL9. The $\Phi(c e a B-l a c Z) 101$ operon fusion was obtained following the infection of strain PAP542 with bacteriophage Mu dX (Baker et al., 1984). The infected cells were plated on MacConkey lactose agar containing $0.1 \mu \mathrm{g}$ mitomycin $\mathrm{C} \mathrm{ml}^{-1}$ with selection for resistance to ampicillin and chloramphenicol (see below). Red $\left(\mathrm{Lac}^{+}\right.$) clones were screened for colicin production in the patch test (Pugsley, 1985), and for their Lac phenotype in the absence of mitomycin C. A single clone out of over 5000 tested fulfilled the requirements for having $\mathrm{Mu} \mathrm{dX}$ inserted into ceaB to give a ceaB-lacZ operon fusion (i.e. $\mathrm{Col}^{-} \mathrm{Imm}^{+}$, and $\mathrm{Lac}^{+}$only in the presence of mitomycin C). Chromosomal DNA from this strain was digested with EcoRI, and the fragments ligated into EcoRI-digested pMBL524, a pBR322 derivative (Silhavy et al., 1984), according to Maniatis et al. (1982). Strain PAP488 was transformed with the ligated mixture with selection for ampicillin resistance on $\mathrm{L}$ agar plates containing $0.1 \mu \mathrm{g}$ mitomycin $\mathrm{C} \mathrm{m}^{-1}$ and $1 \mu \mathrm{g}$ 5-bromo-4-chloro-3-indolyl $\beta$-D-galactoside $\mathrm{ml}^{-1}$ (X-gal). Plasmid pCHAP28 was obtained from one of the blue $\left(\mathrm{LacZ}^{+}\right)$clones which appeared after overnight incubation at $37^{\circ} \mathrm{C}$. Restriction endonuclease mapping of pCHAP28 indicated the structure expected for pMBL524 $\Phi($ ceaB-lacZ), with the insertion site of the Mu dX phage being 50-100 bp downstream from the ClaI site in ceaB. Expression of $\Phi($ cea $B-l a c Z) 101$ in $E$. coli $\mathrm{K} 12$ derivatives carrying pCHAP28 (as measured by specific $\beta$-galactosidase activity; Miller, 1972) was shown to parallel that of colicin E2 production in strains carrying pColE2-P9 or its derivatives, i.e. it was induced by mitomycin $C$ and nalidixic acid, and dependent upon the presence of wild-type $\operatorname{rec} A, l e x A$ and $\operatorname{rec} B$ (for nalidixic acid only) alleles (data not shown).

Plasmid pUH51 [ori pBR322 $\Phi(l a c Z p-E) l a c I^{{ }^{1}}$ ] carries the bacteriophage $\phi X 174$ lysis gene $E$ under the control of the lacZ promoter (Henrich et al., 1983), and was supplied by W. Lubitz (Munich, FRG) and R. Plapp (Kaiserslautern, FRG).

The bacteriophages used were $\lambda, \lambda c i 21, \mathrm{Mu} c t \mathrm{~b} b a^{+}$(W. Schumann. Darmstadt, FRG) and P1 : :Tn921 $\left(\mathrm{Cm}^{\mathrm{r}}\right)$ cts.

Media and growth conditions. L broth (Miller, 1972) was used for most experiments, and was supplemented with $15 \mu \mathrm{g}$ kanamycin $\mathrm{ml}^{-1}, 20$ or $200 \mu \mathrm{g}$ ampicillin $\mathrm{ml}^{-1}, 15 \mu \mathrm{g}$ tetracycline $\mathrm{ml}^{-1}$ or $25 \mu \mathrm{g}$ chloramphenicol ml $\mathrm{m}^{-1}$ as 


\section{Table 1. E. coli K12 strains}

Strain

Genotype, other characteristics, use and reference

BZB1011 gyrA. Host for most Col plasmids

PAP488 rpsL $\Lambda$ (pro-lac). Strain for testing $\Phi(c e a B-l a c Z)$ expression

$\mathrm{BZB} 1019 \mathrm{Met}^{-} h s d R \mathrm{Gal}^{-}$rpsL. Recipient for Col plasmids from strains other than $E$. coli $\mathrm{K} 12$

PC1602 metE Bio- thy $A$ end $A$ (de Geus et al., 1983)

PAP274 $\mathrm{Met}^{+}$pldA* derivative of PCl602 (de Geus et al., 1983)

PAP572 thr-1 leuB6 lac Y Thi ${ }^{-}$supE44 ( $\lambda^{-}$derivative of strain Wl; Ohki et al., 1972) $\dagger$

PAP573 As PAP572 but SDS $\$$ ( $\lambda^{-}$derivative of strain 15; Ohki et al., 1972)

PAP576 As PAP573 but pldA ( $\lambda^{-}$derivative of strain 23; Ohki et al., 1972)

PAP575 As PAP573 but lacking detergent-sensitive phospholipase ( $\lambda^{-}$- derivative of strain 21 ; Ohki et al., 1972)

PAP574 As PAP575 but pldA ( $\lambda^{-}$derivative of strain 17; Ohki et al., 1972)

PAP542 As PAP488 but biuB malA : : (ceaB-celB-ceiB)

${ }^{*} p l d A$ is the structural gene for detergent-resistant phospholipase (Raetz, 1978).

$\dagger$ The original $\lambda$ lysogens described by Ohki et al. (1972) were cured by super-infection with $\lambda \mathrm{i}^{21}$ and screening colonies for absence of immunity to $\lambda$ and to $\lambda \mathrm{i}^{2}$. These strains were originally described as carrying a $\mathrm{mal} A$ mutation, but they are in fact $\mathrm{Mal}^{+} \lambda$ virs.

$\ddagger$ This mutation renders the strains more sensitive to mitomycin $\mathrm{C}$. The increased sensitivity to mitomycin $\mathrm{C}$ and to SDS is only overcome in our derivatives by the absence of the detergent-sensitive phospholipase (unpublished data).

\section{Table 2. Col plasmids}

Plasmid

pColE2-P9

pColE2-CA42

pAPIP219

pCHAP 16

pCHAP23

pCHAP28

pAPIP421

pAPIP408
Structure, origin and reference

Wild-type ColE2 from Shigella sonnei P9; ceaB $B^{+}$ceiB $B^{+}$celB $B^{+}$(Pugsley \& Schwartz, 1983a; Watson et al., 1983)

Wild-type ColE2 from E. coli CA42; ceaB ${ }^{+}$ceiB $B^{+}$celB $B^{+}$(Watson et al., 1983)

pColE2-P9:: Tn5; ceaB $B^{+}$cei $B^{+}$cel $B^{+}$(Pugsley \& Schwartz, 1983a)

pBR322-pColE2-P9 recombinant; tet $^{+}$bla $^{+}$ceaB $B^{+}$ceiB $B^{+}$celB ${ }^{+}$(Cole et al., 1985)

pEMBL9; $\Phi\left(\right.$ lac Zp-ceiB ${ }^{+}-$celB $\left.^{+}\right)$bla ${ }^{+}$(Pugsley \& Schwartz, 1983b, 1984)* ori pBR322; $\Phi\left(\right.$ ceaB-lacZ) 101 bla ${ }^{+\dagger}$

pBR322-pColN-284 recombinant; $\mathrm{cna}^{+} \mathrm{cni}^{+} \mathrm{cnl}^{+} \mathrm{bla}^{+}:$:Tn5 (neo $\left.{ }^{+}\right)$(Pugsley, 1984b)

pColE1-K53:: $\operatorname{Tn} 5 ;$ ceaA $A^{+}$ceiA ${ }^{+}$cel $A^{+}$

* E. coli $\mathrm{K} 12$ strains carrying this plasmid also carried pAPIP502 (lacl $\left.I^{9}\right)$. The presence of lac $I^{9}$ was apparently unnecessary for the maintenance of pCHAP23 in other strains, presumably because their own lacI $I^{+}$alleles were more able to repress $\Phi(\operatorname{lac} Z-c e l B)$ than the $E$. coli K 12 lac $I^{+}$allele (see Pugsley \& Schwartz, $1983 b$ ).

$\dagger$ Details of the construction and analysis of this plasmid are given in Methods.

appropriate for a given plasmid or bacteriophage (see above). Minimal medium was M63 (Miller, 1972) containing $1 \%$ (v/v) glycerol. Media were solidified with $1.6 \%(\mathrm{w} / \mathrm{v})$ agar where appropriate. Broth cultures were grown at $37^{\circ} \mathrm{C}$ with good aeration, and mitomycin $\mathrm{C}$ (usually $0.5 \mu \mathrm{g} \mathrm{ml}^{-1}$ ) was added when the $\mathrm{OD}_{600}$ reached $0 \cdot 15 \cdot 0 \cdot 2$. Changes in OD were then recorded at 20-30 min intervals. A decline in OD is referred to here as lysis or partial lysis, although this term is not strictly correct (see Pugsley, 1984a). IPTG (1 mM) was used to induce $\Phi\left(\right.$ lac $\left.Z_{p}-E\right)$ or $\Phi\left(\right.$ lac $\left.Z_{p}-c e l B\right)$ expression.

Assals. Colicin was assayed by the spot dilution method (Pugsley \& Rosenbusch, 1981). In most cases, comparisons of colicin production by ColE2 ${ }^{+}$E. coli $\mathrm{K} 12$ and other strains were based on the analyses of total TCA-precipitated proteins in the entire culture or in cell-free medium by SDS-PAGE (Pugsley \& Schwartz, 1984). For the direct comparison of colicin production and stability in ColE2 ${ }^{+}$E. coli $\mathrm{K} 12$ and $E$. coli $\mathrm{O} 2$, cells were grown in $\mathrm{I}$, broth or M63 glycerol medium containing mitomycin C. After $70 \mathrm{~min}$, samples were withdrawn, washed twice with M63 medium and resuspended in the same medium containing ${ }^{1+} \mathrm{C}$-labelled amino acids $\left(50 \mu \mathrm{Ci} \mathrm{ml}{ }^{-1}\right.$; $\left.1.85 \mathrm{MBq} \mathrm{m}^{-1}\right)$ (CEA, France) and incubated at $37^{\circ} \mathrm{C}$ for $15 \mathrm{~min}$. These cells were then returned to the main culture, and samples were withdrawn immediately and at subsequent intervals for the analysis of total culture proteins by SDS-PAGE and autoradiography (Pugsley \& Schwartz, 1983a). $\beta$-Galactosidase activity was assayed according to Miller (1972). Extracellular $\beta$-galactosidase activity was assayed as described previously (Pugsley \& Rosenbusch, 1981), and the release of $\beta$ and $\beta^{\prime}$ subunits of RNA polymerase was detected by SDS-PAGE. $o$-Nitrophenyl $\beta$-D-galactoside (ONPG) permeation was determined by comparing the rates of ONPG hydrolysis (Miller, 1972) by intact and chloroform/SDS-lysed, IPTG-induced cells taken from $\mathbf{L}$ broth cultures growing in the presence or absence of mitomycin $\mathrm{C}$. The background permeability coefficient (rate in intact/lysed cells) in wildtype $E$. coli $\mathrm{K} 12$ was $5-8 \%$. A similar coefficient was also obtained with uninduced ColE $2^{+}$strains. Lysozyme and 
SDS sensitivity were indicated by lysis of cultures growing in the presence of mitomycin C plus $25 \mathrm{~mm}^{-\mathrm{MgSO}_{4}}$ $\left(\mathrm{Mg}^{2+}\right.$ prevents 'lysis' resulting from mitomycin $\mathrm{C}$ induction of colicin operon expression). SDS $(1 \%)$ or lysozyme $\left(50 \mu \mathrm{g} \mathrm{ml}^{-1}\right)$ were added after $3 \mathrm{~h}$ incubation. Changes in viability were computed by plating out dilutions of cultures on $\mathrm{L}$ agar plates and counting colonies formed by surviving cells after overnight incubation at $37^{\circ} \mathrm{C}$. Results are presented as the reduction in viability relative to the highest viable count obtained in the first 2-3 h of mitomycin C induction. Lipid analyses were done essentially as described previously (Pugsley \& Schwartz, 1984). Cultures were prelabelled with $\left[{ }^{1+} \mathrm{C}\right]$ acetic acid $\left(20-50 \mu \mathrm{Ci} \mathrm{ml} l^{-1} ; 0.74-1.85 \mathrm{MBq} \mathrm{ml}^{-1}\right)(\mathrm{CEA}$, France) before addition of mitomycin $\mathrm{C}$. The solvent used for most TLC analyses was the chloroform $/ \mathrm{methanol} /$ acetic acid/water $(65: 25: 2: 6$, by vol.) system used previously (Pugsley \& Schwartz, 1984), but other systems described by Ames (1968) were used in attempts to identify minor lipids. Lipid standards, phosphatidylethanolamine (PE), lysoPE, phosphatidylserine (PS), lysoPS, phosphatidylglycerol (PG), lysoPG and phosphatidylcholine, were from Serva (FRG) or Sigma. TLC plates were developed with iodine, molybdenum blue or ninhydrin (Skipski \& Barclay, 1969) before being exposed to X-ray film.

Plasmids. Plasmids were extracted by the method of Holmes \& Quigley (1981), and analysed by restriction endonuclease digestion and agarose gel electrophoresis as described by Maniatis et al. (1982). Transformation, with selection for antibiotic resistance or for immunity to a partially purified preparation of colicin E2-P9, was generally as described by Maniatis et al. (1982), except that solutions containing $50 \mathrm{mM}-\mathrm{Tris} / \mathrm{HCl}(\mathrm{pH} 7 \cdot 4), 5 \mathrm{~mm}$ $\mathrm{MgCl}_{2}$ and 10 or $100 \mathrm{mM}^{-\mathrm{CaCl}_{2}}$ were used for strains which were exceptionally difficult to transform. Colicin production by $\mathrm{Col}^{+}$transformants were tested by the patch method (Pugsley, 1985), and plasmids were extracted from recipients and analysed as above to confirm that major rearrangements had not occurred. Plasmid copy numbers were estimated by comparing plasmid yields (as determined by agarose gel electrophoresis) from cultures grown under identical conditions.

\section{RESULTS}

\section{Further studies with ColE2 ${ }^{+}$E. coli $\mathrm{K} 12$}

The basic characteristics associated with colicin E2 production and release by $E$. coli $\mathrm{K} 12$ have already been documented (Pugsley, 1984a; Pugsley \& Schwartz, 1984; Cole et al., 1985). Our earlier results implicated phospholipase A1-A2 (the pldA gene product) as the cause of the most prominent changes in envelope phospholipid composition which occurred immediately prior to colicin release, namely a reduction in PE content, and increases in lysoPE and free fatty acid (FFA) content (Pugsley \& Schwartz, 1984; Pugsley, 1984a). As a result of more recent studies with other ColE2 ${ }^{+}$strains (see below), and subsequently with ColE2 ${ }^{+}$E. coli K12, we have detected increases in the amounts of a second lipid accompanying colicin release from mitomycin C-induced cells (Fig. 1). This as-yet unidentified lipid migrated close to lysoPE and PS on thin-layer chromatographs. It gave positive reactions with molybdenum blue and with ninhydrin, indicating the presence of phosphate and amine groups (Skipski \& Barclay, 1969). Its appearance, like that of lysoPE and FFA, was dependent on the presence of a functional pld $A$ gene in the chromosome, and of a functional celB (lysis) gene on the ColE2 plasmid (data not shown). This lipid (hereafter referred to as lipid $Y$ ) was also present in increased amounts after induction of $\Phi($ lac Z-celB) in E. coli K12(pCHAP23) (data not shown).

Increases in lysoPE, FFA and lipid Y content were also observed when E. coli $\mathrm{K} 12 \lambda^{+}$was treated with mitomycin C (see also Sakakibara et al., 1972), or when E. coli K12 Mu cts Ap ${ }^{\mathrm{r}}$ or $\mathrm{P} 1 \mathrm{cts} \mathrm{Cm}^{\mathrm{r}}$ lysogens were induced by raising the incubation temperature from $30^{\circ} \mathrm{C}$ to $42^{\circ} \mathrm{C}$. Similarly, induced expression of the bacteriophage $\phi$ X174 gene $E$ in $E$. coli K12(pUH51) (lacZ$E$ ) also resulted in increases in lysoPE, FFA and lipid Y content (W. Lubitz and co-workers, unpublished observations), as did a $5 \mathrm{~min} 56^{\circ} \mathrm{C}$ heat-shock in cultures of wild-type E. coli $\mathrm{K} 12$ (data not shown). In every case, these changes did not occur in derivatives carrying the pldAI mutation. The presence of a second mutation affecting the detergent-sensitive phospholipase (Table 1) did not affect the appearance of increased amounts of these products (data not shown).

The effect of copy number on the expression of $\Phi(c e a B-l a c Z) 101$ was determined using derivatives of PAP488 with the operon fusion in the chromosome or on pCHAP28 (see Methods). In mitomycin $\mathrm{C}$-induced cultures, the level of $\beta$-galactosidase activity was approximately 25 -fold higher in the strain carrying pCHAP28. This figure agrees reasonably well with estimates of pCHAP28 copy number per chromosome (data not shown). A strain devoid of the colicin E2 receptor protein $(\mathrm{BtuB})$ and carrying the colicin E2 operon recombined 


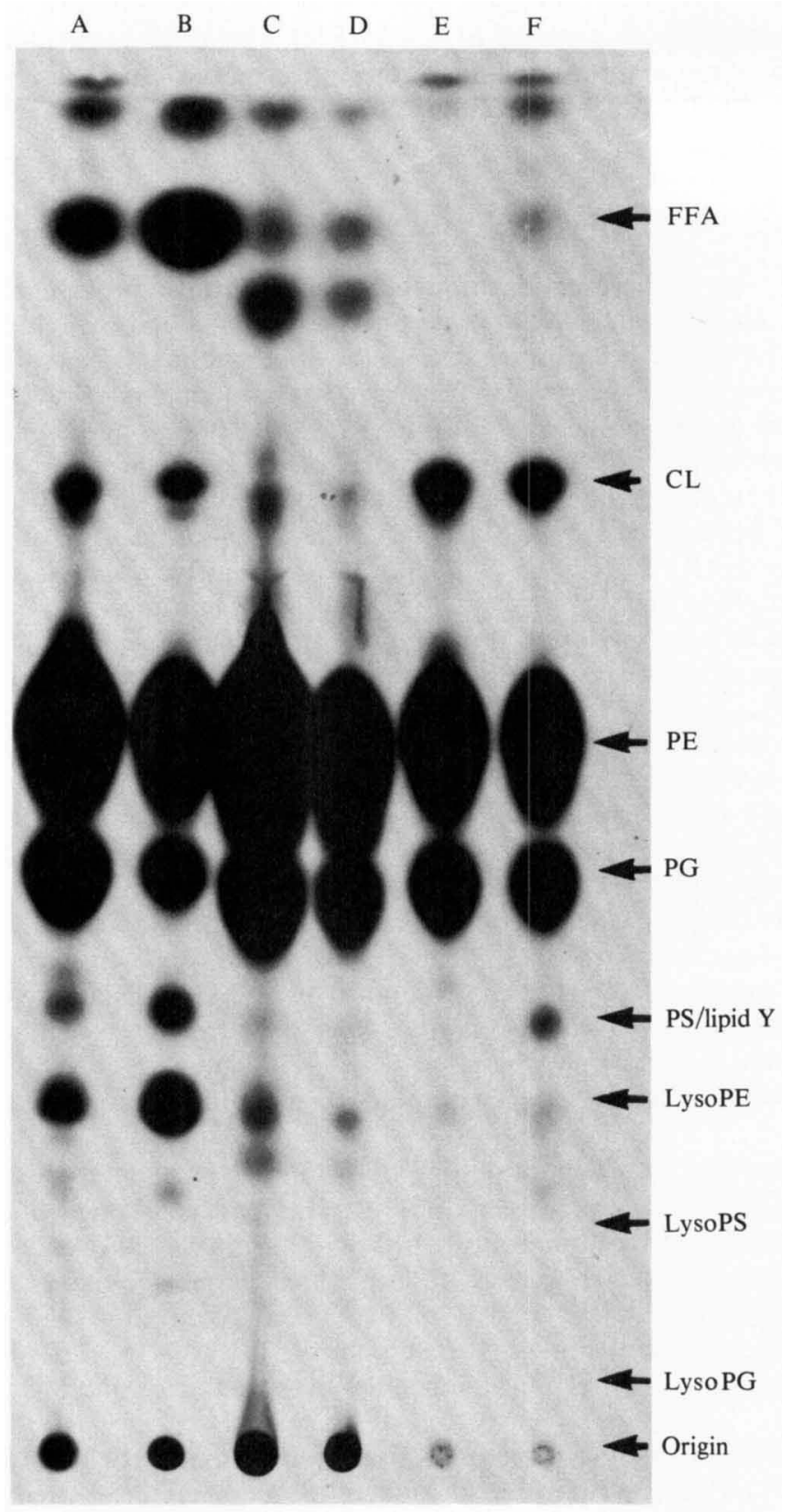

Fig. 1. TLC of chloroform/methanol extracts from $\left[{ }^{1+C}\right]$ acetate-labelled cells of $E$. coli $\mathrm{K} 12$ (pColE2P9) (lanes A, B), Erwinia carotovora 3937(pAPIP219) (lanes C, D) or Salmonella typhimurium S/756 (natural $\mathrm{Col}^{+}$strain) (lanes E, F) grown for $4 \mathrm{~h}$ in $\mathrm{L}$ broth in the absence (lanes A, C, E) or presence (lanes B, D, F) of $0.5 \mu \mathrm{g}$ mitomycin $\mathrm{C} \mathrm{ml}^{-1}$. Note the relatively high amounts of lysoPE, lipid $\mathrm{Y}$ and FFA in uninduced $E$. coli $\mathrm{K} 12(\mathrm{pColE} 2-\mathrm{P} 9)$, which is due to spontaneous induction of colicin production and release as the cells near the end of exponential growth. CL, cardiolipin.

into the chromosomal malA locus also produced less colicin than strains carrying pColE2-P9 or pCHAP 16, but in this case the amounts of colicin recovered after $3 \mathrm{~h}$ of mitomycin $\mathrm{C}$ induction were 50 - to 150 -fold higher in cultures of cells carrying the plasmid; this is considerably greater than the difference predicted by the higher operon copy number in these strains. Indeed, mitomycin C-induced cultures of strain PAP542 (btuB malA : :ceaB-ceiB-celB) did not produce 
sufficient colicin E2 to be detected by SDS-PAGE of whole cell extracts, did not show any changes in phospholipid composition and, significantly, released less than $5 \%$ of their colicin into the growth medium. Reductions in ColE2 plasmid copy number will therefore affect colicin release in a similar way.

\section{Analysis of other ColE2+ strains}

Various ColE2 ${ }^{+}$strains representing different members of the family Enterobacteriaceae were compared with $\mathrm{ColF} 22^{+} E$. coli $\mathrm{K} 12$ with respect to colicin production and release, and associated characteristics. The cultures were grown in $\mathrm{L}$ broth with or without $0.5 \mu \mathrm{g}$ mitomycin $\mathrm{C} \mathrm{ml}^{-1}$ as inducer. Two sets of strains were tested. The first comprised ten natural ColE $2{ }^{+}$strains which, with the exception of Shigella sonnei P9 (ColE2-P9, Collb-P9), produced only one colicin and carried a single species of small, high-copy-number potential Col plasmid (see below). As shown in Table 3, all of these strains, like E. coli K 12(pAPIP219), produced and released large amounts of colicin E2, and became sensitive to SDS. Only Shigella sonnei strains P9 and 1291, and E. coli CA42 showed any signs of a decline in culture turbidity, extensive changes in lysoPE content or substantial reductions in viability up to $6 \mathrm{~h}$ after addition of mitomycin $\mathrm{C}$. Indeed, increases in lysoPE content could not be detected at any time in any of the Salmonella typhimurium ColE2+ strains, and increases in lipid $\mathrm{Y}$ and FFA content were far less prominent than in E. coli $\mathrm{K} 12$ ColE2 ${ }^{+}$(Fig. 1).

Plasmids extracted from the ColE2 ${ }^{+}$Salmonella typhimurium strains were transferred to E. coli K12 strain BZB1019 by transformation with selection for colicin E2 immunity (Methods). The recipients produced and released colicin $\mathrm{E} 2$ in response to mitomycin $\mathrm{C}$ induction in the same way as $E$. coli $\mathrm{K} 12$ (pColE2-P9), i.e. including production of lysoPE and partial lysis. Restriction endonuclease analysis of these plasmids indicated that they were either pColE2-P9-like or pColE2-CA42-like (Pugsley \& Schwartz, 1983a; Watson et al., 1983) (Table 3), with differences in restriction endonuclease cleavage patterns being noted only with enzymes with several cleavage sites in the respective plasmids (data not shown). In particular, the colicin, immunity and lysis gene regions of all plasmids (Cole et al., 1985) were apparently highly conserved. Thus, it would appear that the differences between E. coli K $12 \mathrm{ColE}^{+}$and Salmonella typhimurium $\mathrm{ColE} 2{ }^{+}$strains were due to host cell factors rather than to differences in the Col plasmids they carried.

The use of higher concentrations of mitomycin $C$ to induce colicin production did not cause partial lysis of the Salmonella typhimurium ColE $2^{+}$strains (data not shown), nor did it result in an increase in the amount of lysoPE appearing before or during colicin release (data not shown). However, these cells were shown to have a phospholipase similar to that of $E$. coli $\mathrm{K} 12$ by the fact that the appearance of lysoPE, lipid Y and FFA was induced to the same extent as in $E$. coli $\mathrm{K} 12$ by heat-shock treatment (Fig. 2). We were unable to verify that lysis protein was being produced by these cells, due to technical difficulties in detecting low molecular weight proteins in these cells.

These studies indicated that some natural ColE2+ strains did not behave in the same way as ColE2 ${ }^{+}$E. coli $\mathrm{K} 12$ after mitomycin $\mathrm{C}$ induction. We therefore tested other strains of Enterobacteriaceae which were converted to ColE2 ${ }^{+}$by transformation with the pColE2-P9 derivatives pAPIP219(ColE2::Tn5) or pCHAP16(pBR322 pColE2). Most of these strains responded to mitomycin $\mathrm{C}$ treatment in the same way as $E$. coli $\mathrm{K} 12 \mathrm{ColE} 2^{+}$, except for the fact that the $E$. coli $\mathrm{K} 12$ strains were the only ones which became sensitive to lysozyme (Table 4). However, lysis and increases in lysoPE, lipid $\mathrm{Y}$ and FFA content were sometimes less pronounced than in $E$. coli $\mathrm{K} 12 \mathrm{ColE} 2^{+}$. Some $\mathrm{ColE} 2{ }^{+}$strains produced an additional lipid (lipid Z) after mitomycin C induction (Fig. 3). This lipid usually co-migrated with lysoPS when analysed by TLC. There were also some variations in the apparent specifity of colicin release, with some strains such as Enterobacter cloacae 1028(pAPIP219) releasing only colicin E2 and a protein tentatively identified as elongation factor EFTu in amounts detectable by SDS-PAGE [compare results in Fig. 4 and results with E. coli $\mathrm{K} 12$ strains in Pugsley \& Rosenbusch (1981) and Pugsley \& Schwartz (1984)]. 


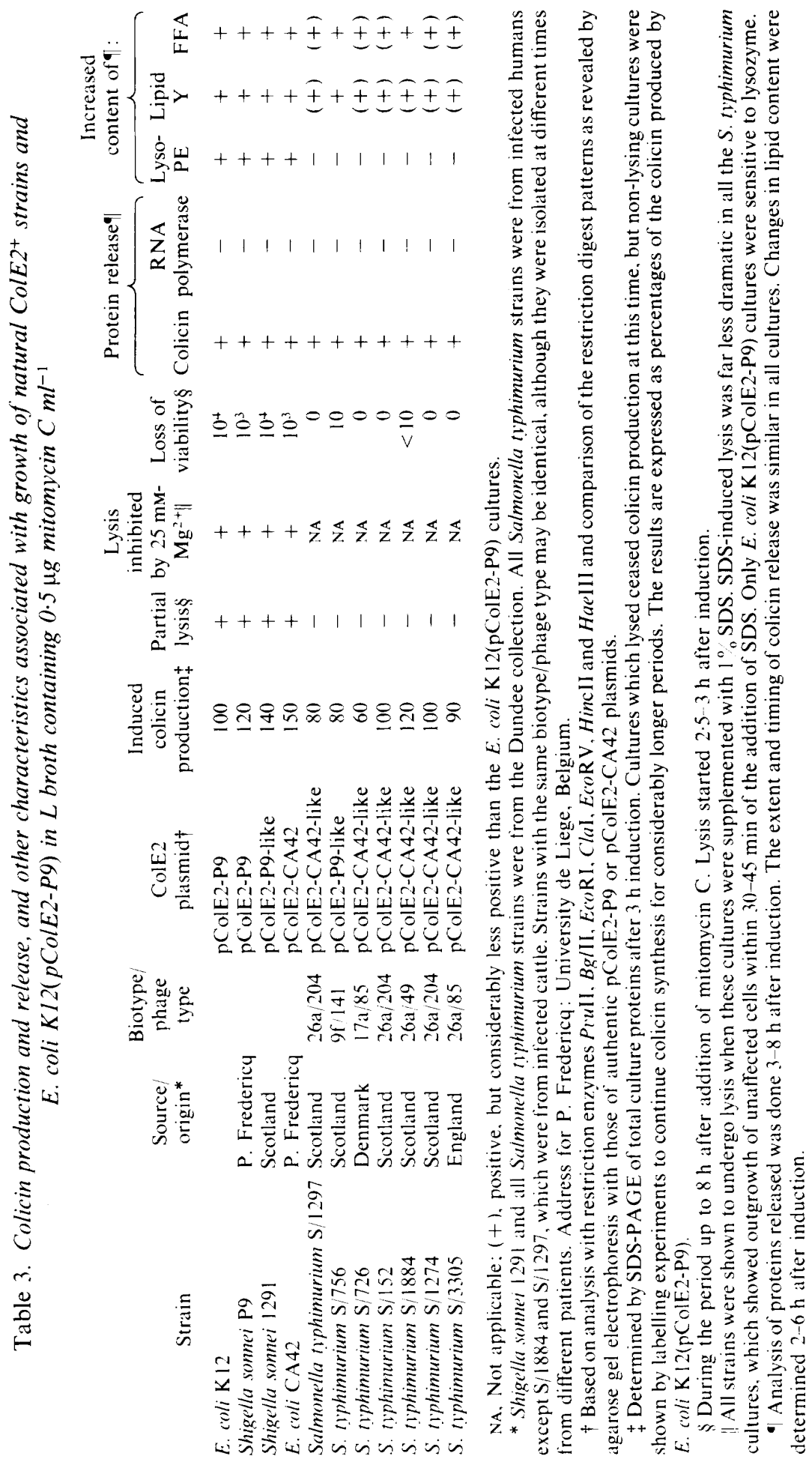


A $\quad$ B $\quad$ C $\quad$ D

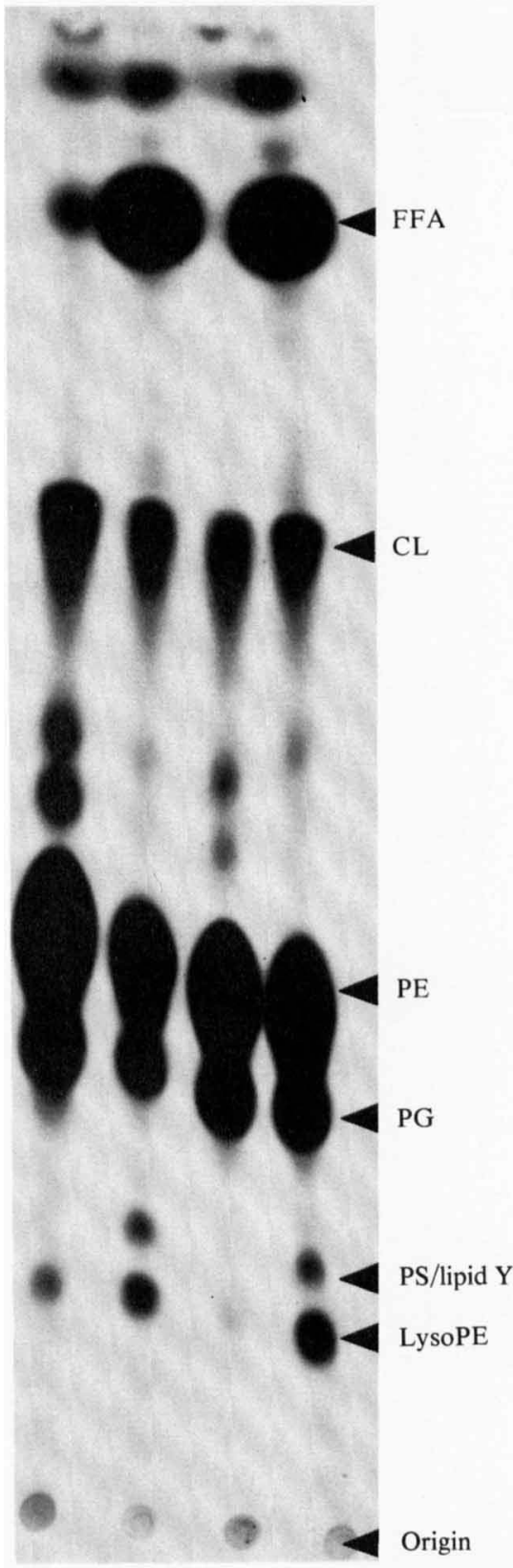

Fig. 2

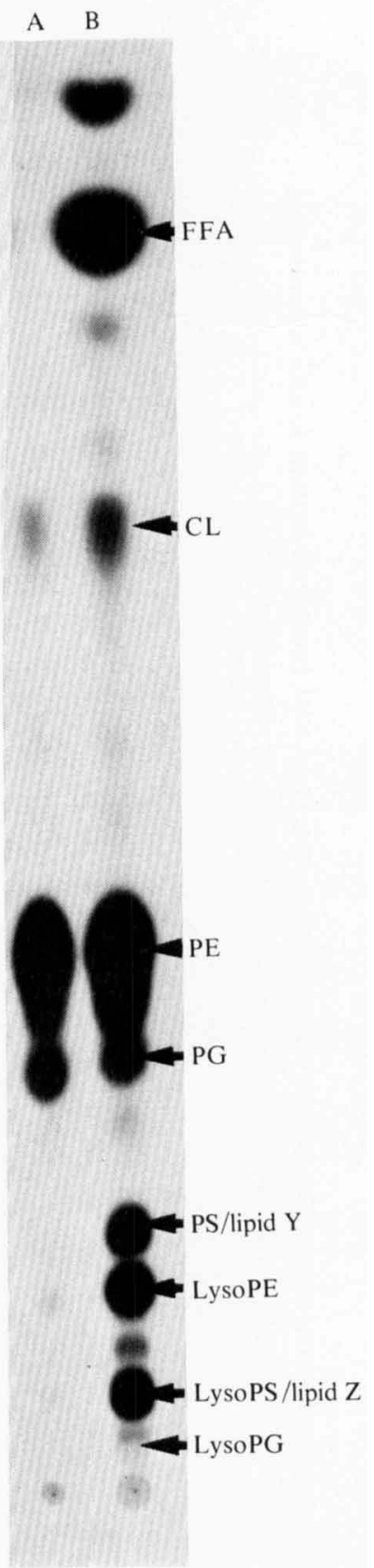

Fig. 3

Fig. 2. TLC of chloroform/methanol extracts from $\left[{ }^{14} \mathrm{C}\right]$ acetate-labelled cells from $\mathrm{L}$ broth cultures of Salmonella typhimurium S/756 (lane A) or the same cells after a 5 min heat-shock and continued incubation (lane B), and of Salmonella typhimurium LT2(pUH51) grown in the absence (lane C) or presence (lane D) of $1 \mathrm{~mm}-\mathrm{IPTG}$ to induce $\Phi(l a c Z-E)$ expression and total lysis. CL, cardiolipin.

Fig. 3. TLC of chloroform/methanol extracts from $\left[{ }^{14} \mathrm{C}\right]$ acetate-labelled cells from $\mathrm{L}$ broth cultures of Klebsiella aerogenes strain 10B(pAPIP219) grown for $4 \mathrm{~h}$ in the absence (lane A) or presence (lane B) of $0.5 \mu \mathrm{g}$ mitomycin $\mathrm{C} \mathrm{m}^{-1}$. Note the presence of lipid $\mathrm{Z}$, which was not detected in the other strains. CL, cardiolipin. 


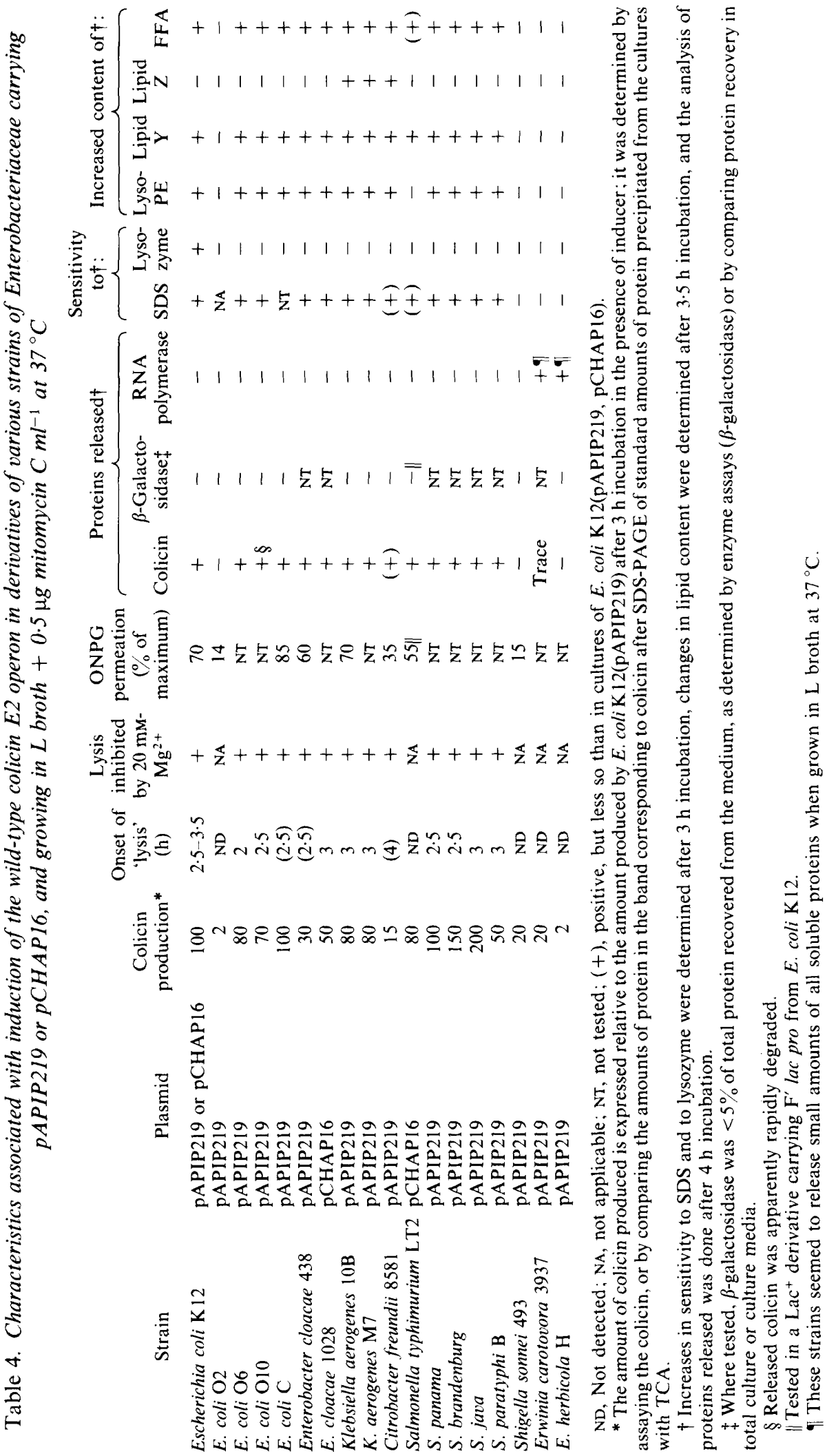




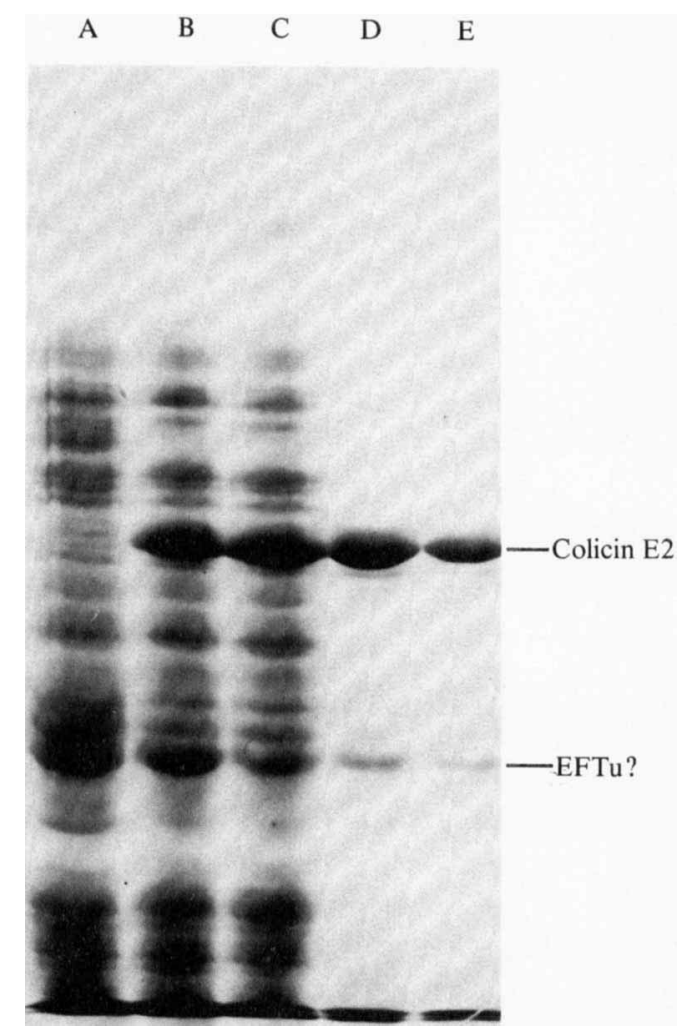

Fig. 4. Production and release of colicin E2 by Enterobacter cloacae 498(pAPIP219). Cells were grown in $\mathrm{L}$ broth (lane $\mathrm{A}$ ), in $\mathrm{L}$ broth $+25 \mathrm{mM}^{-\mathrm{MgSO}_{4}}+0.5 \mu \mathrm{g}$ mitomycin $\mathrm{C} \mathrm{ml} \mathrm{m}^{-1}$ (lanes $\mathrm{B}, \mathrm{D}$ ), or in $\mathrm{L}$ broth $+0.5 \mu \mathrm{g}$ mitomycin $\mathrm{C} \mathrm{ml} \mathrm{m}^{-1}$ (lanes $\mathrm{C}, \mathrm{E}$ ) for $4 \mathrm{~h}$. Samples $\mathrm{A}-\mathrm{C}$ are total culture proteins after precipitation by TCA: samples D and $\mathrm{E}$ are the proteins in the culture medium. All samples were equivalent to $200 \mu \mathrm{l}$ of culture. Note that $\mathrm{Mg}^{2+}$ prevented partial lysis (Table 4) but did not affect colicin production or release.

The response of some of the ColE2 $2^{+}$strains was apparently different from that of $E$. coli $\mathrm{K} 12$ $\mathrm{ColE2}^{+}$(Table 4). Salmonella typhimurium LT2(pCHAP16) resembled the natural ColE2 ${ }^{+}$ Salmonella typhimurium strains (Table 2 ) in all respects, although ColE2 ${ }^{+}$derivatives of other Salmonella species responded to mitomycin $\mathrm{C}$ induction in the same way as ColE2 ${ }^{+} E$. coli $\mathrm{K} 12$ (Table 4). Salmonella typhimurium LT2 produced substantially larger amounts of lysoPE, lipid Y and FFA when subjected to heat-shock or after induction of the $\phi \times 174 E$ gene in derivatives carrying pUH51 (Fig. 2 and not shown). Increasing the amount of mitomycin $\mathrm{C}$ used to induce colicin production in Salmonella typhimurium LT2(pCHAP16) did not elicit partial lysis or the appearance of substantially increased amounts of lysoPE (data not shown). However, Salmonella typhimurium LT2 was slightly more resistant to the growth-reducing effects of mitomycin C than was E. coli $\mathrm{K} 12$, and expression of $\Phi(c e a B-l a c Z) 101$ in derivatives carrying pCHAP28 at a given concentration of mitomycin C was slightly lower in Salmonella typhimurium LT2 than in E. coli K12 (Fig. 5).

ColE2 ${ }^{+}$Shigella sonnei 493 released only trace amounts of colicin even after prolonged incubation in the presence of mitomycin C (Table 4). An unusually high level of resistance was indicated by the absence of growth inhibition by $0.5 \mu \mathrm{g}$ mitomycin $\mathrm{C} \mathrm{ml}^{-1}$, and by the relatively low level of expression of $\Phi(\mathrm{ceaB}-\mathrm{lac} Z) 101$ at this dose of mitomycin C (Fig. 5 and data not shown). Cultures of Shigella sonnei 493(pAPIP219) grown in the presence of $1.5 \mu \mathrm{g}$ mitomycin C $\mathrm{ml}^{-1}$ produced more colicin E2, and released it at the normal time with concomitant partial lysis and increases in lysoPE, lipid Y and FFA content. 


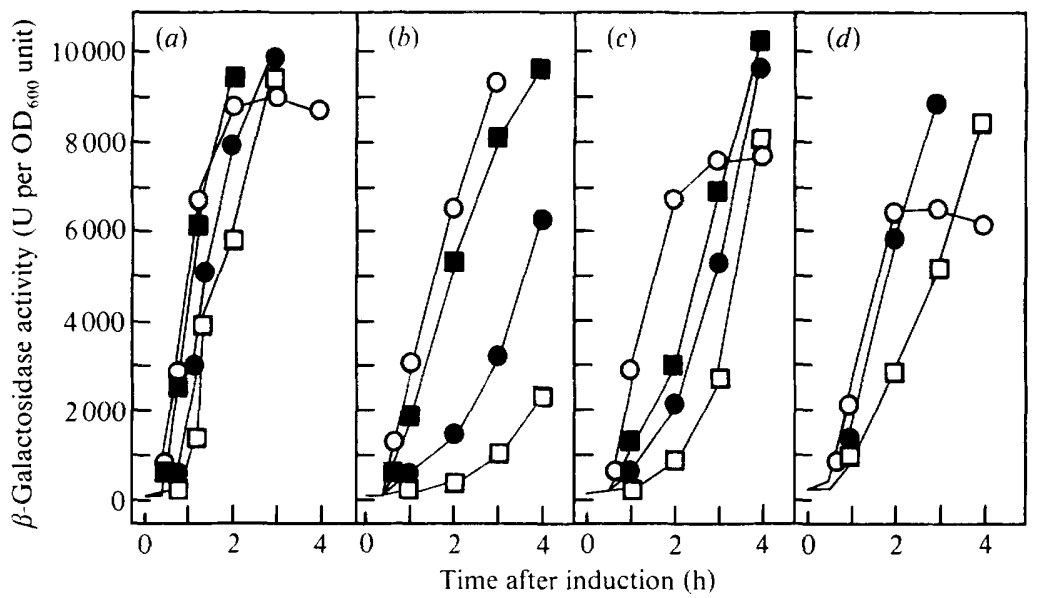

Fig. 5. Expression of $\Phi(c e a B$-lacZ) 101 , encoded by plasmid pCHAP28, in E. coli K12 (a), Shigella sonnei $493(b)$, Salmonella typhimurium LT2 (c) or E. coli 2 2 (d) growing in L broth containing various concentrations of mitomycin $C: 0.5 \mu \mathrm{g} \mathrm{ml}^{-1}(\square), 1 \mu \mathrm{g} \mathrm{ml}^{-1}(\bigcirc), 1.5 \mu \mathrm{g} \mathrm{ml}^{-1}(\square), 5 \mu \mathrm{g} \mathrm{ml}^{-1}(\mathrm{O})$. $\beta$-Galactosidase units (Miller, 1972) were corrected in $(b)$ and $(d)$ by deducting the activity measured in parallel cultures of the same strain without pCHAP28 (these strains carry a chromosomal lac $Z^{+}$ allele).

E. coli $\mathrm{O} 2$ (pAPIP219) was unusual among all of the strains tested in that the amount of colicin produced after mitomycin $\mathrm{C}$ induction was extremely low $[<2 \%$ of that in $E$. coli K12(pAPIP219)], and that it was extremely sensitive to $1 \%$ SDS even in the absence of mitomycin $C$ treatment. Surprisingly, expression of $\Phi(c e a B-l a c Z) 101$ was apparently normal in this strain, and derivatives carrying pAPIP421 (ColN) or pAPIP408 (ColE1) produced relatively large amounts of colicins $\mathrm{N}$ and $\mathrm{E} 1$ respectively, and released these colicins with concomitant lysis and activation of phospholipase (data not shown). Furthermore, E. coli O2(pAPIP219) produced normal amounts of colicin E2 when grown in M63 glycerol medium containing $0.5 \mu \mathrm{g}$ mitomycin $\mathrm{C} \mathrm{m} l^{-1}$, and $\Phi($ lac $Z p-c e l B)$ expression in derivatives carrying pCHAP23 provoked lysis and activation of phospholipase when the cultures were grown in minimal medium, but not in L broth (data not shown; see Methods). pAPIP219 was consistently present at approximately the same copy number as in $E$. coli K12 (data not shown).

E. coli O10(pAPIP219) produced normal amounts of colicin E2 when grown in L broth containing $0.5 \mu \mathrm{g}$ mitomycin $\mathrm{C} \mathrm{ml}^{-1}$, but the colicin which was released was apparently rapidly degraded. A similar phenomenon was reported previously in $E$. coli $\mathrm{K} 12$ derivatives carrying ColE4 or ColE7 plasmids (Pugsley, 1983a).

The two Erwinia strains (Erwinia carotovora 3937 and Erwinia herbicola H) were both incapable of producing large amounts of colicin when transformed with pAPIP219 and grown in the presence of $0.5 \mu \mathrm{g}$ mitomycin $\mathrm{C} \mathrm{ml}^{-1}$. However, the temperature at which these experiments were done was higher $\left(37^{\circ} \mathrm{C}\right)$ than the optimum growth temperature for these strains $\left(30^{\circ} \mathrm{C}\right)$, and they therefore grew very slowly (doubling times at $37^{\circ} \mathrm{C} 90-100 \mathrm{~min}$ compared with 40 $50 \mathrm{~min}$ for $E$. coli $\mathrm{K} 12$ ). Previous experiments with $E$. coli $\mathrm{K} 12$ strains have shown that reductions in growth rate severely reduce the amount of colicin produced. $E$. coli K 12 mutants selected by their survival after mitomycin $\mathrm{C}$ induction of the wild-type colicin operon, or after induction of $\Phi(l a c Z p-c e l B)$, usually grew at slower rates than the parent strains, and did not carry mutations directly related to colicin production and release (unpublished results, see also Pugsley \& Schwartz, 1983b). Furthermore colicin production by E. coli K12 ColE2+ in cultures containing $0.5 \mu \mathrm{g}$ mitomycin $\mathrm{C} \mathrm{ml}^{-1}$ was reduced to $<10 \%$ by lowering the incubation temperature from $37^{\circ} \mathrm{C}$ to $30^{\circ} \mathrm{C}$, and the colicin which was produced was not released. 


\section{DISCUSSION}

This study was initiated in order to test the validity of E. coli $\mathrm{K} 12$ as the model strain for studying the mechanisms of colicin production and release. Our preliminary studies with the strains used here indicated that they represented a fairly homogeneous group with respect to envelope structure; only small variations in minor lipid content and outer membrane protein content were observed (data not shown). In contrast, similar analyses of Aeromonas, Yersinia, and to a lesser extent Serratia strains revealed more striking differences in lipid and protein composition. These strains could not be transformed with ColE2 plasmid derivatives.

Most of the strains we tested were able to produce and release large quantities of colicin E2 when induced with mitomycin C. This implies that they, like E. coli K12 (Pugsley, 1984a), have a LexA protein which represses colicin operon expression, and which is inactivated after induction of the SOS response. In addition, all of the elements necessary for efficient colicin release seem to be present in most of these strains. Variations in the extent of 'lysis' and PldA phospholipase activation may result in part from differences in the extent of ColE2 plasmid lysis gene expression. Measurements of colicin operon expression with operon fusions such as $\Phi($ ceaB-lac $Z) 101$ used here give only indirect indications of the expression of down-stream $c e l B$ expression, but direct measurements of $c e l B$ expression are complicated by the small size of its product, by the need for post-translational processing and by the fact that wild-type $c e l B$ is essential for optimum expression of the entire operon (Oudega et al., 1983; Cole et al., 1985). Sequence analysis of the colicin E2 operon has revealed the existence of a possible transcription terminator (or attenuator) just up-stream from celB (Pugsley, 1984a; Cole et al., 1985); variations in the efficiency of attenuation in the different strains could affect production of the lysis protein in the same way as the reduction in its copy number consequent upon introduction of the colicin E2 operon into the chromosome. Reduced lysis protein production would reduce phospholipase activation and hence colicin release (Pugsley \& Schwartz, 1984).

On the basis of our results with $E$. coli $\mathrm{K} 12$, the appearance of lipid $\mathrm{Y}$ and lysoPE seems to result from the action of PldA phospholipase A on pre-existing phospholipid. ColE2+ Salmonella typhimurium produced only lipid $\mathrm{Y}$, but this may reflect a lower level of phospholipase activity or increased lysoPE turnover. The identity of lipid Y and of lipid Z, which appeared in other strains when they were induced to produce colicin E2, remains unknown; they could correspond to lysoPG and lysoCL respectively, or to intermediates in phospholipid biosynthesis such as PS and lysoPS (Raetz, 1978). Further characterization of these lipids will require their purification and chemical analysis.

A striking difference between $E$. coli $\mathrm{K} 12$ and all other strains tested was that only E. coli $\mathrm{K} 12$ became lysozyme-sensitive after induction of colicin production (Tables 3 and 4). This may reflect the inability of this basic protein to penetrate the side chain LPS residues of 'smooth' strains of Enterobacteriaceae. In all other cases, the strains differed from $E$. coli $\mathrm{K} 12$ in specific details of their response to mitomycin $C$, some of which were not necessarily indicative of overall differences in mechanisms of colicin production and release. In general, we believe that the results are consistent with the model proposed to explain colicin release from $E$. coli $\mathrm{K} 12$ (Pugsley \& Schwartz, 1984; Pugsley, 1984a), and justify the continued use of this strain in future studies.

The impermeability of the cytoplasmic membrane to proteins is apparently not substantially altered when cells release colicin from the cytoplasm. At least four proteins or protein complexes (RNA polymerase, $\beta$-galactosidase, colicin Ia and amylomaltase) remain in the cytoplasm when colicin and cytoplasmic EfTu protein are released (Pugsley \& Rosenbusch, 1981; Pugsley, $1983 b$; M. A. Bloch \& A. P. Pugsley, unpublished results). Colicin Ia and amylomaltase are approximately the same size as the colicin E2-immunity protein complex (mol. wt approximately $70000 ; \mathrm{M}$. A. Bloch, unpublished data), which makes it unlikely that the relatively high specificity of colicin release from the cytoplasm is due solely to its small size (Pugsley, 1984a; Pugsley \& Schwartz, 1985). It seems likely that lysis protein plays a direct role in the transfer of colicin across the cytoplasmic membrane. In contrast, outer membrane permeability is substantially increased. The extremely high amounts of colicin which are released give the impression of high selectivity (Fig. 4), although in reality, most periplasmic 
proteins are quantitatively released along with the colicin (Pugsley \& Rosenbusch, 1981). It seems probable that the presence of increased amounts of lyso lipids is an important feature of this increase in outer membrane permeability (Pugsley \& Schwartz, 1984), as it is in the case of membrane permeabilization by EDTA (Hardaway \& Buller, 1979). It is not known whether other treatments which affect the permeability of the outer membrane to proteins do so by activating phospholipase (Hancock, 1984), but we have recently found that typical periplasmic leaky mutants of $E$. coli $\mathrm{K} 12$, which spontaneously release periplasmic proteins into the growth medium (Hancock, 1984), do not have elevated levels of lysoPE. These mutations ( $r f a, t o l A$ and $t o l B$ ) also have no effect on colicin E2 release in liquid culture (unpublished data). Thus, it would seem that activation of phospholipase is only one of the ways in which the permeability barrier of the Gram-negative outer membrane can be broached.

L. Le Minor (Institut Pasteur) is thanked for supplying some of the strains used in this study. Financial support was provided by grants from the Centre National de la Recherche Scientifique (UA04 1149 and ATP. CP96) and from the Ministere de la Recherche et de la Technologie ( $82 \mathrm{~V}$ 1279). Additional support was provided by the Fondation pour la Recherche Médicale and the Institut Pasteur.

\section{REFERENCES}

AMES, G. F. (1968). Lipids of Salmonella typhimurium and Escherichia coli: structure and metabolism. Journal of Bacteriology 95, 833-843.

Baker, T. A., Howe, M. M. \& Gross, C. A. (1984). $\mathrm{MudX}$, a derivative of $\mathrm{Mudl}\left(\mathrm{lac} A \mathrm{p}^{\mathrm{R}}\right)$ which makes stable lac $Z$ fusions at high temperature. Journal of Bacteriology 156, 970-974.

Cole, S. T., Saint-Joanis, B. \& Pugsley, A. P. (1985). Molecular characterization of the colicin E2 operon and identification of its products. Molecular and General Genetics 198, 465-472.

ne Geus, P., Van Die, H., Bergmans, J., Tommassen, J. \& DE HAaS, G. (1983). Molecular cloning of pldA, the structural gene for outer membrane phospholipase of E. coli K 12. Molecular and General Genetics 190, 150-155.

HaNCOCK, R. E. W. (1984). Alterations in outer membrane permeability. Annual Review of Microbiology 38, 237-264.

Hardaway, K. L. \& Buller, C. S. (1979). Effect of ethylenediaminetetraacetic acid on phospholipids and outer membrane function in Escherichia coli. Journal of Bacteriology 137, 62-68.

Henrich, B., Lubitz, W. \& Plapp, R. (1983). Expression of $\phi \times 174$ lysis gene cloned in different plasmids. In The Target of Penicillin, pp. 197-203. Edited by R. Hakenbeck, J. V. Höltje \& H. Labischinski. Berlin: de Gruyter.

Holmes, D. D. \& Quigley, I. (1981). A rapid boiling method for the preparation of bacterial plasmids. Analytical Biochemistry 114, 193-197.

Lugtenberg, B. \& VAN Alphen, W. (1983). Moleculat architecture and functioning of the outer membrane of Escherichia coli and other Gram-negative bacteria. Biochimica et biophysica acta 737, 51-115.

Maniatis, T., Fritsch, E. F. \& Sambrook, J. (1982). Molecular Cloning, a Laboratory Manual. Cold Spring Harbor, NY: Cold Spring Harbor Laboratory.

Miller, J. H. (1972). Experiments in Molecular Genetics. Cold Spring Harbor, NY: Cold Spring Harbor Laboratory.

OHKI, M., Dol, O. \& NoJima, S. (1972). Mutant of Escherichia coli $\mathrm{K}-12$ deficient for detergent-resistant

phospholipase A. Journal of Bacteriology 110, 864 869.

Oudega, B., Stegehuis, F. \& de Graaf, F. K. (1983). Effect of glucose fermentation on the functioning of protein $\mathrm{H}$, involved in excretion of cloacin DF 13 . FEMS Microbiology Letters 22, 101-108.

Pugsley, A. P. (1983a). Colicin E4-CT9 is proteolytically degraded after discharge from producing cells in liquid cultures. Journal of General Microbiology 129, 833-840.

Pugsley, A. P. (1983b). Obligatory coupling of colicin release and lysis in mitomycin-treated $\mathrm{Col}^{+}$Escherichia coli. Journal of General Microbiolog. 129, 19211928.

Pugsley, A. P. (1984a). The ins and outs of colicins. Part I. Production and translocation across membranes. Microbiological Sciences 1, 168-175.

Pugsley, A. P. (1984b). Genetic analysis of ColN plasmid determinants for colicin production, immunity and release. Journal of Bacteriology 158, 523-529.

PugsLey, A. P. (1985). Escherichia coli K12 strains for use in the identification and characterization of colicins. Journal of General Microbiology 131, 369376.

Pugsley, A. P. \& Rosenbusch, J. P. (1981). Release of colicin E2 from Escherichia coli. Journal of Bacteriology 147, 186-192.

Pugsley, A. P. \& Schwartz, M. (1983a). A genetic approach to the study of mitomycin-induced lysis of Escherichia coli strains which produce colicin E2. Molecular and General Genetics 190, 366-372.

Pugsley, A. P. \& Schwartz, M. (1983b). Expression of a gene in a 400 base pair fragment of colicin plasmid ColE2-P9 is sufficient to cause host cell lysis. Journal of Bacteriology 156, 109-114.

Pugsley, A. P. \& SchwartZ, M. (1984). Colicin E2 release: lysis, leakage or secretion? Possible role of a phospholipase. EMBO Journal 3, 2393-2397.

Pugsley, A. P. \& Schwartz, M. (1985). Export and secretion of proteins by bacteria. FEMS Microbiology Reviews 1, 3-38.

RAETZ, C. R. H. (1978). Enzymology, genetics and 
regulation of membrane phospholipid biosynthesis in Escherichia coli. Microbiological Reviens 42, 614 659.

Raibald, O., Mock, M. \& Schwartz, M. (1984). A technique for integrating any DNA fragment into the chromosome of Escherichia coli. Gene 29, 231241 .

SaKakibara, Y., Dol, O. \& Nojima, S. (1 272). Growth of bacteriophage lambda in phospholipase A-less mutants. Biochemical and Biophysical Research Communications 46, 1434-1440.
Silhavy, T. J., Berman, M. L. \& ENQList, L. W (1984). Experiments with Gene Fusions. Cold Spring Harbor, NY: Cold Spring Harbor Laboratory.

SKIPSKI, V. P. \& Barclay, M. (1969). Thin layer chromatography of lipids. Methods in Enzymology 14, 530-598.

WATSON, R., KONASARKA-KOZLOWSKA, M., IYER, V. N., Yaguchi, M. \& Vinsentin, L. P. (1983). Comparison of plasmids ColE2-P9 and ColE2-CA42 and their immunity proteins. Journal of Bacteriology $153,1552-1557$. 